\title{
Determination of Uridine in Human Plasma by HPLC and its Application in Citicoline Sodium Pharmacokinetics and Bioequivalence Studies
}

Keguang Chen ${ }^{1}$, Xiaoyan Liư ${ }^{2}$, Chunmin $\mathrm{Wei}^{2}$, Guiyan Yuan², Rui Zhang ${ }^{2}$, Rong Li ${ }^{2}$, Benjie Wang ${ }^{2}$ and Ruichen Guo ${ }^{2 *}$

${ }^{1}$ College of pharmacy, Shandong University. Jinan 250012, P.R. of China

${ }^{2}$ Institute of Clinical Pharmacology, Qilu Hospital of Shandong University, Jinan 250012, P.R. of China

\begin{abstract}
A simple and rapid high performance liquid chromatography (HPLC) method was developed and validated to determine uridine, metabolite of citicoline, in human plasma, and applied to the pharmacokinetics and bioequivalence studies of citicoline sodium tablet and capsule. Uridine and amoxicillin (used as internal standard, IS) were extracted from plasma by simple protein precipitation with perchloric acid. The separation was performed on a Phenomenex kinetex $\mathrm{C} 18(100 \times 4.6 \mathrm{~mm}, 2.6 \mu \mathrm{m})$ column, with a mobile phase of $0.05 \mathrm{M}$ phosphate buffer (Potassium dihydrogen phosphate, adjusted $\mathrm{pH}$ to 3.5 by phosphate) - Methanol $(98: 2, \mathrm{~V} / \mathrm{V})$, and delivered at the flow rate of $0.8 \mathrm{~mL} / \mathrm{min}$. The calibration curve was linear over uridine concentration range of $0.05-2 \mu \mathrm{g} / \mathrm{mL}(r>0.99)$, The main pharmacokinetic parameters of citicoline sodium tablet and capsule were as follows, $t_{1 / 2}(4.393 \pm 2.526)$ and $(4.857 \pm 4.503) h, T_{\text {mx }}$ (3.354 \pm 1.118$)$ and $(3.688 \pm 1.082) \mathrm{h}, \mathrm{Cmax}(1.956 \pm 0.402)$ and $(2.070 \pm 0.619) \mu \mathrm{g} / \mathrm{mL}, A U C 0-12(12.774 \pm 3.222)$ and $(13.992 \pm 3.953) \mu \mathrm{g} / \mathrm{mL}^{*} \mathrm{~h}, \mathrm{AUC0} \infty(16.015 \pm 5.647)$ and $(17.198 \pm 6.672) \mu \mathrm{g} / \mathrm{mL}{ }^{*} \mathrm{~h}$, respectively. The two-one side t-test analysis showed that the confidential intervals of Cmax, AUC0-12, AUC0 $\infty$ of citicoline sodium tablet and capsule were $(89.5 \% \sim 102.1 \%),(85.3 \% \sim 97.5 \%),(85.3 \% \sim 102.9 \%)$, respectively. The relative bioavailability of citicoline sodium tablets was $92.7 \%$. The tablet and capsule were bioequivalence.
\end{abstract}

Keywords: Uridine; Citicoline sodium; HPLC; Pharmacokinetics; Bioequivalence

\section{Introduction}

Citicoline (CDP-choline or cytidine $5^{1}$ - diphosphocholine) is both an endogenous intermediate in the biosynthesis of phosphatidylcholine (PC) $[1,7,8]$ which may act as a neuroprotector in several models of neurodegeneration and use as a therapeutic agent to treat stroke and brain injury [1], or in combined with levodopa, to treat Parkinson's disease (PD) [9].CDP-choline is readily metabolized to cytidine monophosphate (CMP) and phosphocholine, and then dephosphorylated to form cytidine and choline after exogenously administered in rats [14]. But in human, cytidine undergoes rapid catabolism by cytidine deaminase (CD) [3]. The deaminated product uridine $[1,2]$, which is the central intermediate $[4,5]$ and also named as the precursor of UTP, CTP, and CDP-choline [6], increased proportionally to the doses orally administered, and then was used as matabolite of CDP-choline to evaluate the characteristics of the pharmacokinetics and bioequivalence of CDP-choline oral preparations (shown in Figure 1).

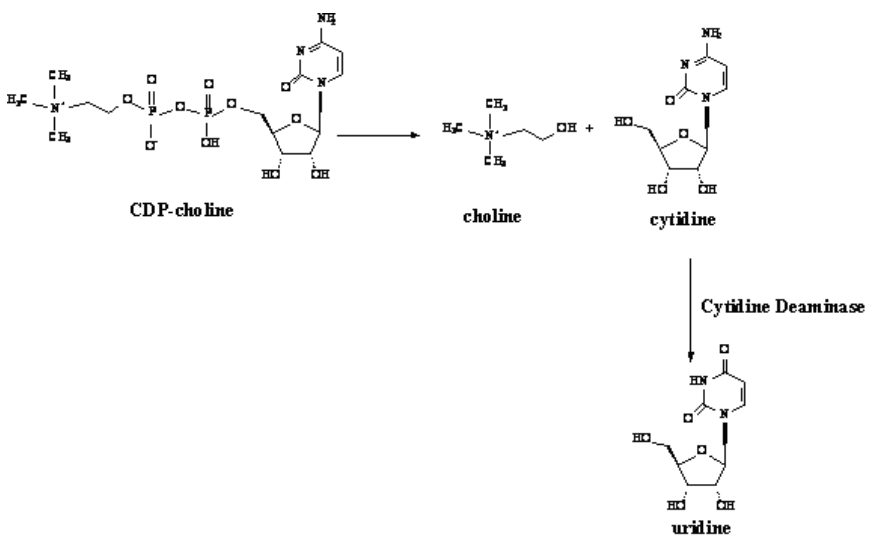

Figure 1: The biotransformation of CDP-choline in rats and in human.
The present study aimed to develop a simple and rapid HPLC method for the analysis of uridine in plasma and to evaluate the bioequivalence of citicoline sodium tablet (test) and capsule (reference) in Chinese healthy volunteers.

\section{Materials and Methods}

\section{Instruments and reagents}

Waters 2695 Separations Module equipped with 2996 UV Detector (supplied by American Waters company) was used for separating and quantifying uridine in human plasma.

Citicoline sodium tablet as test, $100 \mathrm{mg}$ per tablets, was provided by Beijing Zhongxin Pharmaceutical Co.LTD., Citicoline sodium capsule as reference, $100 \mathrm{mg}$ per capsules, was provided by Qilu Pharmaceutical Co.LTD., Uridine standard (purity 99\%, batch LO70J02) was from J\&K CHEMICAL LTD. Amoxicillin standard was used as internal standard (IS) and obtained from National Institute for the Control of Pharmaceutical and Biological Products. Methanol, HPLC grade, was purchased from J.T Baker company, USA. Potassium dihydrogen phosphate, analytical grade, was purchased from Economic and Technological Development Zone Fine Chemicals Factory of Laiyang. Blank human plasma was from Shandong blood center (P. R. of China).

*Corresponding author: Ruichen Guo, Institute of Clinical Pharmacology, Qilu Hospital of Shandong University, Jinan 250012, P.R. of China. Tel: (0531) 82169636; Fax: (0531) 86109975; E-mail: grc7636@126.com

Received April 08, 2011; Accepted May 19, 2011; Published May 25, 2011

Citation: Chen K, Liu X, Wei C, Yuan G, Zhang R, et al. (2011) Determination of Uridine in Human Plasma by HPLC and its Application in Citicoline Sodium Pharmacokinetics and Bioequivalence Studies. J Bioequiv Availab 3: 072-076. doi:10.4172/jbb.1000062

Copyright: () 2011 Chen K, et al. This is an open-access article distributed unde the terms of the Creative Commons Attribution License, which permits unrestricted use, distribution, and reproduction in any medium, provided the original author and source are credited. 

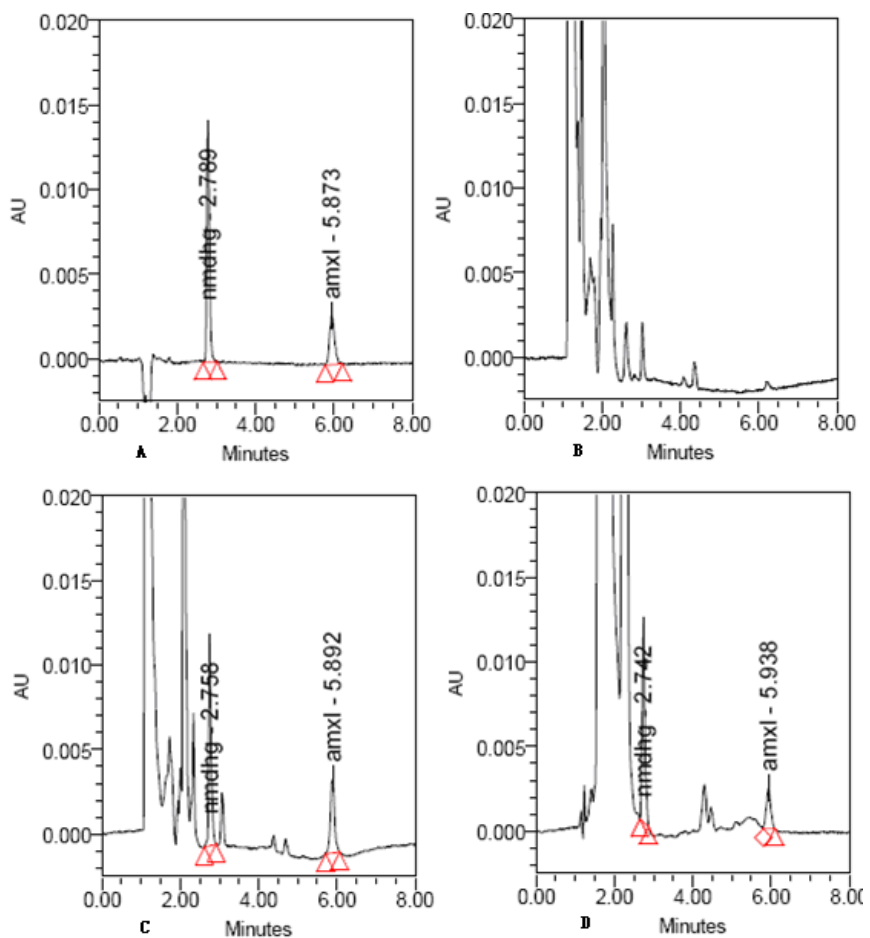

Figure 2: Typical chromatograms of uridine $\left(1 \mu \mathrm{g} \cdot \mathrm{mL}^{-1}\right)$ and IS (amoxicillin) (10 $\left.\mu \mathrm{g} \cdot \mathrm{mL}^{-1}\right)$ standard $(\mathrm{A})$, blank plasma $(B)$, blank plasma spiked with uridine $(1$ $\left.\mu \mathrm{g} \cdot \mathrm{mL}^{-1}\right)$ and IS $\left(10 \mu \mathrm{g} \cdot \mathrm{mL}^{-1}\right)(\mathrm{C})$ and plasma spiked with IS from volunteer No $9,2 \mathrm{~h}$ after administration $600 \mathrm{mg}$ of citicoline sodium tablet (D).

\section{Chromatographic conditions}

The separation was performed on Phenomenex kinetex $\mathrm{C}_{18}$ $(100 \times 4.6 \mathrm{~mm}, 2.6 \mu \mathrm{m})$ column. The mobile phase was daily prepared and composed of $0.05 \mathrm{~mol} / \mathrm{L}$ phosphate buffer (Potassium dihydrogen phosphate, adjusted $\mathrm{pH}$ to 3.5 by phosphate) - Methanol $(98: 2, \mathrm{~V} / \mathrm{V})$ at the flow rate of $0.8 \mathrm{~mL} / \mathrm{min}$. The detection was occured at $260 \mathrm{~nm}$ and the injection volume was $20 \mu \mathrm{L}$.

Preparation of stock solution, calibration standard and quality control samples

A given amount of uridine was dissolved in mobile phase to get 1 $\mathrm{mg} / \mathrm{mL}$ uridine stock solutions, then diluted to get its working solutions $(1.5,3,6,15,30,48$ and $60 \mu \mathrm{g} / \mathrm{mL})$. Calibration curve and quality control (QC) samples $(0.1,0.5$ and $1.6 \mu \mathrm{g} / \mathrm{mL})$ were prepared in bulk by spiking appropriate amount of working solutions with blank human plasma. Amoxicillin (IS) was dissolved in mobile phase to get $60 \mu \mathrm{g} / \mathrm{mL}$ stock solutions. All stock and working solutions were stored at $4 \mu$ until analysis.

\section{Sample disposition}

A liquor of $0.3 \mathrm{~mL}$ plasma spiked with $60 \mu \mathrm{L}$ IS and mixed, then $50 \mu \mathrm{L}$ perchloric acid (10\%) was added, vortexed for $2 \mathrm{~min}$, and centrifuged at $10800 \mathrm{r} / \mathrm{min}$ for $10 \mathrm{~min}$. The supernatant was transferred and $20 \mu \mathrm{L}$ was injected for analysis.

\section{Method validation}

Specificity: The specificity was evaluated by comparing typical chromatograms of uridine and IS (amoxicillin), blank plasma, blank plasma spiked with uridine and IS, and plasma spiked with IS from volunteer No 9, $2 \mathrm{~h}$ after administration $600 \mathrm{mg}$ of citicoline sodium tablet.

Recovery, precision and accuracy: The extraction recoveries of uridine and the IS were determined by comparing the peak areas of extracted plasma spiked with uridine and I.S. at three QC levels with those of post-extraction blank plasma spiked with corresponding concentration of uridine and IS. Five replicates of each QC level were disposed with the established sample disposition procedure.

The precision and accuracy of the method were evaluated by analyzing plasma QC samples of $0.1,0.5$ and $1.6 \mu \mathrm{g} / \mathrm{mL}$. Five replicate quality control samples at each concentration were analysed in one day for intra-day precision or in three consecutive days for inter-day precision.

Stability: Uridine QC sample of $0.1,0.5$ and $1.6 \mu \mathrm{g} / \mathrm{mL}$ were analyzed before or after freezing at $-20^{\circ} \mathrm{C}$ for one day, for 7 days and for 14 days, or after one or two freeze-thawing clycles and in auto-sampler at room temperature for 8 hours after extraction to evaluate its stability.

LLOQ: The Lower Limit of quantization (LLOQ) was evaluated by analyzing five replicates of spiked plasma sample at the uridine concentration of $0.05 \mu \mathrm{g} / \mathrm{mL}$.

Qualitycontrol: The quality control (QC) samples were incorporated in each analytical run at concentrations of $0.1,0.5,1.6 \mu \mathrm{g} /$ $\mathrm{mL}$. The relative standard deviation (RSD) of QC samples should be within $15 \%$ except for $0.1 \mu \mathrm{g} \cdot \mathrm{mL}^{-1}$, where it should not deviate by more than $20 \%$.

Pharmacokinetic study: Twenty-four male healthy Chinese volunteers, aged $24.8 \pm 2.3$ years, height $175.2 \pm 5.0 \mathrm{~cm}$ and body weight $69.1 \pm 5.6 \mathrm{~kg}$, were physically examined and screened and written informed consents were obtained. The study protocol was approved by the Ethics Committee of the Second Hospital of Shandong University and the study was conducted in accordance with the Declaration of Helsinki.

All qualified volunteers were randomly divided into two groups. A single dose of $600 \mathrm{mg}$ of citicoline sodium tablet or capsule was orally administered after overnight fasting. A liquor of blood samples were collected before and $0.5,1.0,1.5,2.0,3.0,4.0,5.0,6.0,8.0,10.0$ and 12.0 $\mathrm{h}$ after citicoline sodium test or reference, and plasma was separated, then frozen immediately at $-20^{\circ} \mathrm{C}$ until analysis. The washing period was 7 days. Standard meals and a given amount of water were provided 4 hours after administration, and no coffee, smoke, chocolate or other food were allowed. All volunteers were under supervision of physicians for any possible adverse events.

Drug and Statistics (DAS, version 2.0.1, by Sun Ruiyuan, et al, P.R. of China) was used to calculate its main pharmacokinetic parameters $\left(\mathrm{t}_{1 / 2}, \mathrm{AUC}_{0-12}\right.$ and $\left.\mathrm{AUC}_{0-\infty}\right) . \mathrm{C}_{\max }$ and $\mathrm{T}_{\max }$ were as observed.

\section{Results}

\section{Specificity}

Under above chromatographic conditions, uridine and IS were eluted at 2.7 and $5.7 \mathrm{~min}$, respectively. The typical chromatograms of uridine standard (A) and IS (amoxicillin) (B), blank plasma (C), blank plasma spiked with uridine and IS (D), and plasma spiked with IS from volunteer No 9, $2 \mathrm{~h}$ after administration of citicoline sodium (E) were shown in Figure 2. 
Citation: Chen K, Liu X, Wei C, Yuan G, Zhang R, et al. (2011) Determination of Uridine in Human Plasma by HPLC and its Application in Citicoline Sodium Pharmacokinetics and Bioequivalence Studies. J Bioequiv Availab 3: 072-076. doi:10.4172/jbb.1000062

\begin{tabular}{|c|c|c|c|c|c|c|c|}
\hline \multirow[b]{2}{*}{$C(\mu \mathrm{g} / \mathrm{mL})$} & \multirow[b]{2}{*}{ Recovery \% } & \multicolumn{3}{|l|}{ Intra-day } & \multicolumn{3}{|l|}{ Inter-day } \\
\hline & & \multicolumn{3}{|c|}{$\bar{x} \pm \mathrm{SD} \quad$ Accuracy $\%$ RSD $\%$} & \multicolumn{3}{|c|}{$\bar{x} \pm \mathrm{SD} \quad$ Accuracy $\%$ RSD $\%$} \\
\hline 0.1 & 99.66 & $0.099 \pm 0.01$ & 99.0 & 10.56 & $0.1 \pm 0.01$ & 100 & 9.99 \\
\hline 0.5 & 102.09 & $0.51 \pm 0.048$ & 102.0 & 9.33 & $0.51 \pm 0.049$ & 102.0 & 9.77 \\
\hline 1.6 & 95.57 & $1.41 \pm 0.04$ & 88.1 & 2.86 & $1.56 \pm 0.15$ & 97.5 & 9.71 \\
\hline
\end{tabular}

Table 1: The intra-day and inter-day precisions and recoveries of uridine in plasma $(n=5)$.

\begin{tabular}{|c|c|c|c|c|c|c|c|c|}
\hline \multirow{3}{*}{$\begin{array}{l}\mathrm{C}(\mu \mathrm{g} / \mathrm{mL}) \\
0.1\end{array}$} & \multicolumn{2}{|c|}{ Fresh samples } & \multicolumn{2}{|c|}{ Freezed one day } & \multicolumn{2}{|c|}{ Freezed 7 days } & \multicolumn{2}{|c|}{ Freezed 14 days } \\
\hline & \multicolumn{2}{|c|}{$\bar{x} \pm \mathrm{SD} \quad \mathrm{RSD} \%$} & \multicolumn{2}{|c|}{$\bar{x} \pm \mathrm{SD} \quad \mathrm{RSD} \%$} & \multicolumn{2}{|c|}{$\bar{x} \pm \mathrm{SD} \quad \mathrm{RSD} \%$} & \multicolumn{2}{|c|}{$\bar{x} \pm \mathrm{SD} \quad \mathrm{RSD} \%$} \\
\hline & $0.102 \pm 0.007$ & 6.83 & $0.097 \pm 0.008$ & 8.64 & $0.097 \pm 0.014$ & 14.65 & $0.095 \pm 0.006$ & 6.28 \\
\hline 0.5 & $0.51 \pm 0.036$ & 7.04 & $0.49 \pm 0.02$ & 4.03 & $0.55 \pm 0.18$ & 3.32 & $0.53 \pm 0.027$ & 5.11 \\
\hline 1.6 & $1.61 \pm 0.076$ & 4.76 & $1.46 \pm 0.085$ & 5.82 & $1.73 \pm 0.047$ & 2.71 & $1.71 \pm 0.061$ & 3.56 \\
\hline
\end{tabular}

Table 2: The stability of uridine in plasma after 14 days storage at $-20^{\circ} \mathrm{C}(\mathrm{n}=5)$.

\begin{tabular}{|c|c|c|c|c|c|c|}
\hline \multirow{3}{*}{$\begin{array}{l}C(\mu \mathrm{g} / \mathrm{mL}) \\
0.1\end{array}$} & \multicolumn{2}{|c|}{ One freeze-thawing cycle } & \multicolumn{2}{|c|}{ Two freeze-thawing cycles } & \multicolumn{2}{|c|}{ Post-extracted samples } \\
\hline & \multicolumn{2}{|c|}{$\bar{x} \pm \mathrm{SD} \quad \mathrm{RSD} \%$} & \multicolumn{2}{|c|}{$\bar{x} \pm \mathrm{SD} \quad \mathrm{RSD} \%$} & \multicolumn{2}{|c|}{$\bar{x} \pm \mathrm{SD} \quad \mathrm{RSD} \%$} \\
\hline & $0.089 \pm 0.0026$ & 2.92 & $0.105 \pm 0.0102$ & 9.68 & $0.113 \pm 0.004$ & 3.53 \\
\hline 0.5 & $0.477 \pm 0.055$ & 11.54 & $0.53 \pm 0.06$ & 11.34 & $0.501 \pm 0.007$ & 1.38 \\
\hline 1.6 & $1.67 \pm 0.06$ & 3.58 & $1.62 \pm 0.052$ & 3.23 & $1.654 \pm 0.067$ & 4.05 \\
\hline
\end{tabular}

Table 3: The stability of uridine in plasma after one or two freeze-thaw cycles or after extraction $(n=5)$.

\begin{tabular}{|l|l|l|}
\hline Parameter & Test & Reference \\
\hline $\mathrm{t}_{1 / 2}(\mathrm{~h})$ & $4.39 \pm 2.52$ & $4.86 \pm 4.50$ \\
\hline$T_{\max }(\mathrm{h})$ & $3.35 \pm 1.12$ & $3.69 \pm 1.08$ \\
\hline $\mathrm{AUC}_{0-12}(\mu \mathrm{g} / \mathrm{mL} \cdot \mathrm{h})$ & $12.77 \pm 3.22$ & $13.99 \pm 3.95$ \\
\hline $\mathrm{AUC}_{0 \sim \infty}(\mu \mathrm{g} / \mathrm{mL} \cdot \mathrm{h})$ & $16.02 \pm 5.65$ & $17.20 \pm 6.67$ \\
\hline $\mathrm{C}_{\max }(\mu \mathrm{g} / \mathrm{mL})$ & $1.96 \pm 0.40$ & $2.07 \pm 0.62$ \\
\hline
\end{tabular}

Table 4: Main pharmacokinetic parameters of uridine after single oral dose of $600 \mathrm{mg}$ citicoline sodium test and reference $(\bar{x} \pm \mathrm{s}, \mathrm{n}=24)$.

\begin{tabular}{|l|l|l|l|}
\hline Parameters & $\mathrm{t}_{\mathrm{L}}$ & $\mathrm{t}_{\mathrm{H}}$ & $90 \%$ Confidence intervals \\
\hline $\mathrm{C}_{\max } / \mu \mathrm{gg} / \mathrm{mL}$ & 8.16 & 10.56 & $89.5 \% \sim 102.1 \%$ \\
\hline $\mathrm{AUC}_{0-12} / \mu \mathrm{\mu g} / \mathrm{mL} \cdot \mathrm{h}$ & 3.38 & 8.12 & $85.3 \% \sim 97.5 \%$ \\
\hline $\mathrm{AUC}_{0 \sim \infty} / \mu \mathrm{g} / \mathrm{mL} \cdot \mathrm{h}$ & 2.88 & 5.27 & $85.3 \% \sim 102.9 \%$ \\
\hline
\end{tabular}

Table 5: The two-one side t-test and $90 \% \mathrm{Cls}$ of natural log-transformed parameters result.

\section{Calibration curves and LLOQ}

Human plasma calibration standards of uridine $(0.05,0.1,0.2,0.5$, $1,1.6$ and $2 \mu \mathrm{g} / \mathrm{mL}$ ) were prepared by spiking $10 \mu \mathrm{L}$ of working solutions $(1.5,3,6,15,30,48$ and $60 \mu \mathrm{g} / \mathrm{mL})$ of uridine into $290 \mu \mathrm{L}$ blank plasma, respectively, to eliminate the plasma matrix effect. The plasma samples were extracted and analyzed in accordance to the processes described above. Calibration curve was constructed with the peak area ratio of uridine to IS versus uridine concentration. The linearity was observed in the concentration range of $0.05-2 \mu \mathrm{g} / \mathrm{mL}$. The regressive equation was $\mathrm{Y}=2.10 \mathrm{X}+0.57(\mathrm{r}=0.9928)(\mathrm{n}=5)$. The method offered a LLOQ of $0.05 \mu \mathrm{g} / \mathrm{mL}$ uridine (RSD 9.88\%).

\section{Recovery, precision and accuracy}

The recoveries of uridine at concentrations of $0.1,0.5$ and $1.6 \mu \mathrm{g} /$ $\mathrm{mL}$ and the intra-day and inter-day precisions assessed by analyzing nominal uridine concentrations of $0.1,0.5$ and $1.6 \mu \mathrm{g} / \mathrm{mL}$ in plasma were shown in Table 1.

\section{Stability}

Uridine was stable after storing for one days, 7 days and 14 days at $-20^{\circ} \mathrm{C}$, as shown in Table 2 , and stable or after one or two freezethaw cycles and in auto-sampler at room temperature for 8 hours after extraction, as shown in Table 3.

\section{Pharmacokinetics}

Uridine plasma concentration were analyzed using the developed HPLC method. The mean plasma concentration-time profile of 24 healthy volunteers after sigle oral dose of $600 \mathrm{mg}$ of citicoline sodium test or reference was shown in Table 3. The main pharmacokinetic parameters were summarized in Table 4.

\section{Bioequivalence}

The $\mathrm{C}_{\max }, \mathrm{AUC}_{0-12}$ and $\mathrm{AUC}_{0 \sim \infty}$ of citicoline sodium test and reference were evaluated by ANOVA and two-one side t-test and the results were shown in Table 5. No significant differences were found between citicolin sodium test and reference, suggesting that citicolin sodium capsules and tablets were bioequivalent.

\section{Discussion}

Although citicoline sodium oral preparations are marketed in China for many years, information regarding the pharmacokinetics and bioequivalence of these formulations in humans has not been reported to date. The aim of this study was to compare the pharmacokinetics and bioavailability of the tablet (test) and capsule (reference) formulations of citicoline sodium in healthy chinese volunteers.

Some reserches showed that when administered orally or by 
injection, exogenous CDP-choline in rats is completely metabolized to choline and cytidine. These intermediates enter the circulation, cross the blood-brain barrier, and are converted in part to acetylcholine, phosphocholine, and CTP. Then, phosphocholine and CTP combine to form endogenous CDP-choline, which reacts with DAG to form PC $[1,4,8]$. Information on CDP-choline's disposition and pharmacokinetic characteristics in human body is extremely incomplete.

Choline is a polar, non-volatile molecule, and cannot be measured by chromatographic analysis because of lacks chromophore, its small size and widely present in mammalian species [10]. Some improved methods included automated protein precipitation with acetonitrile followed by normal phase LC separation and MS/MS detection were reported [13]. The technical complexity of LC-MS/MS and its cost considerations limit the availability of this method in many biomedical laboratories interested in choline analysis.

It was confirmed that the principal circulating metabolites of exogenous CDP-choline in humans are uridine and choline [1]. Brain phosphatidylcholine (PC) synthesis utilizes both the uridine formed from the metabolism of exogenous CDP-choline and UMP, and the choline transfered from that of CDP-choline [11].

In some mammalian species, including humans, cytidine is apparently and minimally transported across the blood-brain barrier. The brain capillaries lacking the high-affinity CNT1 transport protein were known to mediate pyrimidine transport. In contrast, uridine, which is readily formed from cytidine, can enter into brain via an unsaturated transport system [12]. Moreover, in both humans and gerbils, unlike rats, oral CDP-choline provides with uridine rather than cytidine in blood. Most cytidine analogue drugs are metabolized by cytidine deaminase (CD; EC3.5.4.5) [3].

Blockage of enzymes responsible for the metabolism of uridine in plasma samples, as well as rapid separation of the blood cells from the plasma upon collection the operations of sample disposition on ice were recommended to prevent uridine loss degeneration. Uridine is a watersoluble substances. Enoxacin, ciprofloxacin, levofloxacin, gatifloxacin and amoxicillin were tried as I.S. Amoxicillin was selected because of its stable structure, appropriate retention time $(<6 \mathrm{~min})$ and excellent peak shape.

Citicoline was determinated by HPLC method with phosphate buffer-methanol (95:5) as mobile phase to control the qualities of the preparations in ChP. The PBS and methanol were also selected as mobile phase, but different ratio, and different $\mathrm{pH}$ to obtain the best seperation. The mobile phase, when composed of PBS $(0.05 \mathrm{M}, \mathrm{pH} 3.5$ adjusted with phosphoric acid) and methanol (98:2), was found that uridine and I.S. were well separated with other endogenous substances in plasma, and the retention time of interest and I.S. were all less than $6 \mathrm{~min}$.

The uridine also exist endogenously, equal amount of the blank plasma were used to establish calibration or quality control samples to avoid the interference of endogenous uridine. $10 \mu \mathrm{L}$ of uridine standard solution concentrations of $1.5,3,6,15,30,48,60 \mu \mathrm{g} / \mathrm{mL}$ was taken from each concentration and mixed with $290 \mu \mathrm{L}$ blank plasma to obtain the calibration curve and qulity control samples.

Several extraction methods were examined to evaluate the matrix effects and to get high recoveries. Matrix interference and low recoveries were observed with solid phase extraction, and liquid-liquid extraction (LLE), respectively. A direct protein precipitation method was developed, which was easy, sample time-saving, with high recoveries, and no deproteinization agents with hazardous organic solvents were needed.
Due to the food might affect the metabolism of citicoline, the volunteers underwent a $10 \mathrm{~h}$ overnight fast before administration, no food allowed within 4 hours after administration, and all volunteers were given the same standardized foods in the two study periods to minimize any effects of food.

The pharmacokinetic data showed that citicoline sodium was rapidly absorbed after oral dose and completely metabolized to uridine, to reach the $\mathrm{C}$ of uridine within $3.4 \mathrm{~h}$ after citicoline sodium administration. The $t_{1 / 2}$ of the uridine was no more than $5 \mathrm{~h}$, indicating that the elimination of uridine was fast. One week washout period was sufficient to clear the residue compound of the previous period, which represents undetectable plasma concentration at baseline of the second period in all subjects.

\section{Conclusion}

No significant differences were found in uridine mean plasma concentration-time curves for test and reference formulation of citicoline sodium $600 \mathrm{mg}$ in 24 healthy volunteers. The calculated 90\% CIs for mean $\mathrm{C}_{\max }, \mathrm{AUC}_{0-12}$ and $\mathrm{AUC}_{0 \sim \infty}$ of two drugs lay within the accepted range of $80-125 \%$. Therefore, it could be concluded that the two citicoline sodium preparations (test and reference) were bioequivalent.

\section{References}

1. Wurtman RJ, Regan M, Ulus I, Yu L (2000) Effect of oral CDP-choline on plasma choline and uridine levels in humans. Biochemical Pharmacology 60: 989-992.

2. Richardson UI, Watkins CJ, Pierre C, Ulus IH, Wurtman RJ (2003) Stimulation of CDP-choline synthesis by uridine or cytidine in PC12 rat pheochromocytoma cells. Brain Res 971: 161-167.

3. Beumer JH, Eiseman JL, Parise RA, Florian JA Jr, Joseph E, et al. (2008) Plasma pharmacokinetics and oral bioavailability of 3,4,5,6-tetrahydrouridine a cytidine deaminase inhibitor, in mice. Cancer Chemother Pharmacol 62: $457-$ 464

4. Ulus IH, Watkins CJ, Cansev M, Wurtman RJ (2006) Cytidine and uridine increase striatal CDP-choline levels without decreasing acetylcholine synthesis or release. Cellular and Molecular Neurobiology 26: 4-6.

5. Williams MG, palandra J, Shobe EM (2003) Rapid determination of rat plasma uridine levels by HPLC-ESI-MS utilizing the Captiva filter plates for sample preparation. Biomed Chromatogr 17: 215-218.

6. Wang L, Albrecht MA, Wurtman RJ (2007) Dietary supplementation with uridine5-monophosphate (UMP), a membrane phosphatide precursor, increases acetylcholine level and release in striatum of aged rat. Brain Res 1133: 42-48.

7. Wang L, Pooler AM, Albrecht MA, Wurtman RJ (2005) Dietary uridine-5 monophosphate supplementation increases potassium-evoked dopamine release and promotes neurite outgrowth in aged rats. Journal of Molecula Neuroscience 27: 137-146.

8. Barrachina M, Secades J, Lozano R, Gómez-Santos C, Ambrosio S, et al (2002) Citicoline increases glutathione redox ratio and reduces caspase- 3 activation and cell death in staurosporine-treated SH-SY5Y human neuroblastoma cells. Brain Research 957: 84-90.

9. Barrachina M, Domínguez I, Ambrosio S, Secades J, Lozano R, et al. (2003) Neuroprotective effect of citicoline in 6-hydroxydopamine-lesioned rats and in 6 -hydroxydopamine-treated SH-SY5Y human neuroblastoma cells. Journal of the Neurological Sciences 215: 105-110.

10. Yue BF, Pattison E, Roberts WL, Rockwood AL, Danne O, et al. (2008) Choline in whole blood and plasma: sample preparation and stability. Clinical Chem 54: 590-593.

11. Holquin S, Huang Y, Liu J, Wurtman R (2008) Chronic administration of DHA and UMP improves the impaired memory of environmentally impoverished rats. Behavioural Brain Research 191: 11-16.

12. Teather LA, Wurtman RJ (2006) Chronic administration of UMP ameliorates the impairment of hippocampal-dependent memory in impoverished rats. JNutr 36: $2834-2837$ 
Citation: Chen K, Liu X, Wei C, Yuan G, Zhang R, et al. (2011) Determination of Uridine in Human Plasma by HPLC and its Application in Citicoline Sodium Pharmacokinetics and Bioequivalence Studies. J Bioequiv Availab 3: 072-076. doi:10.4172/jbb.1000062

13. Adamczyk M, Brashear RJ, Mattingly PG, Tsatsos PH (2006) Homogeneous chemiluminescent assays for free choline in human plasma and whole blood. Anal Chim Acta 579: 61-67.
14. Cansev M, Yilmaz MS, Ilcol YO, Hamurtekin E, Ulus IH (2007) Cardiovascular effects of CDP-choline and its metabolites: Involvement of peripheral autonomic nervous system. Eur J Pharmacol 577: 129-142. 